\title{
Language Discordance and Telephone Interpretation Complicates Pain Neuroscience Education in Physical Therapy Management of a Patient with Acute Low Back Pain
}

\author{
Margaret C. Burns \\ University of Colorado, margaret.c.burns@cuanschutz.edu \\ Tamara S. Struessel \\ University of Colorado, tami.struessel@cuanschutz.edu
}

Follow this and additional works at: https://nsuworks.nova.edu/ijahsp

Part of the Physical Therapy Commons

\section{Recommended Citation}

Burns MC, Struessel TS. Language Discordance and Telephone Interpretation Complicates Pain Neuroscience Education in Physical Therapy Management of a Patient with Acute Low Back Pain. The Internet Journal of Allied Health Sciences and Practice. 2022 Jan 03;20(1), Article 10.

This Case Study is brought to you for free and open access by the College of Health Care Sciences at NSUWorks. It has been accepted for inclusion in Internet Journal of Allied Health Sciences and Practice by an authorized editor of NSUWorks. For more information, please contact nsuworks@nova.edu. 


\title{
Language Discordance and Telephone Interpretation Complicates Pain Neuroscience Education in Physical Therapy Management of a Patient with Acute Low Back Pain
}

\begin{abstract}
Purpose: Pain neuroscience education (PNE) is an intervention used for musculoskeletal pain to improve understanding of pain processes; PNE can decrease pain levels, improve function, and lower disability. Clear communication between the patient and provider is important for PNE to be an effective intervention. There is a lack of research on how a language discordance may impact that communication, and therefore the effectiveness of PNE. Purposes: 1) describe the physical therapist management of a Spanish speaking patient with acute low back pain (LBP) while using an off-site telephone interpreting service and 2) examine how PNE treatment was impacted by a language discordance. Methods: A female in her early 40's presented with LBP two months after a motor vehicle accident. A systems review revealed comorbidities of class 1 obesity and prediabetes and a language discordance between the provider and patient, necessitating the use of a telephone interpreter. While acute LBP is usually self-limiting, the language discordance and comorbidities were expected to negatively impact her functional prognosis. Intervention included PNE, strengthening, directional preference exercises, graded exposure, and body mechanics training. Results: Within 5 weeks, the patient's self-perceived disability as reported by the Spanish translated and culturally adapted Oswestry Disability Index, thoracolumbo-pelvic hip range of motion, and perceived levels of pain improved significantly. Conclusion: The link between clarity of communication while utilizing PNE and patient comprehension, outcomes, and satisfaction is unclear. While more time consuming, PNE delivered via translations services appears to be an effective physical therapy intervention. However, further research is needed and it is important for physical therapy providers to consider how language discordance could impact the effectiveness of PNE.
\end{abstract}

\author{
Author Bio(s) \\ Margaret Burns, PT, DPT \\ Tami Struessel, PT, DPT, OCS, MTC
}




\title{
1IJAHSP ${ }^{m}$ \\ The Internet Joumnal of Allied Health Sciences and Practice \\ Dedicated to allied health professional practice and education \\ Vol. 20 No. 1 ISSN 1540-580X
}

\section{Language Discordance and Telephone Interpretation Complicates Pain Neuroscience Education in Physical Therapy Management of a Patient with Acute Low Back Pain}

\author{
Margaret C. Burns \\ Tamara S. Struessel \\ University of Colorado \\ United States
}

\begin{abstract}
Purpose: Pain neuroscience education (PNE) is an intervention used for musculoskeletal pain to improve understanding of pain processes; PNE can decrease pain levels, improve function, and lower disability. Clear communication between the patient and provider is important for PNE to be an effective intervention. There is a lack of research on how a language discordance may impact that communication, and therefore the effectiveness of PNE. Purposes: 1) describe the physical therapist management of a Spanish speaking patient with acute low back pain (LBP) while using an off-site telephone interpreting service and 2) examine how PNE treatment was impacted by a language discordance. Methods: A female in her early 40's presented with LBP two months after a motor vehicle accident. A systems review revealed comorbidities of class 1 obesity and prediabetes and a language discordance between the provider and patient, necessitating the use of a telephone interpreter. While acute LBP is usually selflimiting, the language discordance and comorbidities were expected to negatively impact her functional prognosis. Intervention included PNE, strengthening, directional preference exercises, graded exposure, and body mechanics training. Results: Within 5 weeks, the patient's self-perceived disability as reported by the Spanish translated and culturally adapted Oswestry Disability Index, thoracolumbo-pelvic hip range of motion, and perceived levels of pain improved significantly. Conclusion: The link between clarity of communication while utilizing PNE and patient comprehension, outcomes, and satisfaction is unclear. While more time consuming, PNE delivered via translations services appears to be an effective physical therapy intervention. However, further research is needed and it is important for physical therapy providers to consider how language discordance could impact the effectiveness of PNE.
\end{abstract}

Keywords: pain neuroscience education, language discordance, physical therapy, acute low back pain 


\section{INTRODUCTION}

A language discordance occurs when a practitioner and patient lack proficiency in the same language. ${ }^{1}$ Language discordance can adversely impact health care services in general. Spanish speaking individuals who did not feel comfortable speaking English and whose providers were not fluent in Spanish, were less likely to receive recommended health care and reported far worse health outcomes. ${ }^{2,3}$ The method of interpretation seems to have an impact, with use of an off-site telephone interpreting service leading to lower patient satisfaction compared to video and in person interpretation. ${ }^{4}$ It is unclear if a language discordance impedes effectiveness of PNE in LBP treatment. ${ }^{5}$

Pain neuroscience education (PNE) is an intervention used to address pain-related psychosocial impairments, showing promise as an intervention for low back pain (LBP). ${ }^{6}$ Approximately $80 \%$ of Americans will experience back pain in their lifetime, with nonspecific acute LBP being the most common presentation. ${ }^{7}$ It is crucial to address psychosocial as well as physical impairments in physical therapist treatment of acute LBP to decrease the risk of transitioning to chronic LBP. ${ }^{8}$ Pain neuroscience education aims to improve patients' understanding of pain by describing the neurobiology and neurophysiology of pain as well as pain processing by the nervous system. ${ }^{9}$ Clear communication between the patient and provider is important for PNE to be an effective intervention. A strong therapeutic alliance and clear explanation improves effectiveness of PNE. ${ }^{10}$

Spanish is the second most common language in the United States. ${ }^{11}$ The high volume of Spanish speakers, as well as research that shows a language discordance often impacts quality of health care, creates a need for a larger knowledge base about the effects of language discordance on physical therapy treatment. Therefore, the purpose of this study is to 1) describe the physical therapist management of a Spanish speaking patient with acute LBP while using an off-site telephone interpreting service and 2) examine how PNE treatment was impacted by a language discordance.

\section{METHODS}

\section{Case Description}

A primary Spanish speaking female in her early 40's, presented to a hospital-based outpatient physical therapy clinic with a referral for acute nonspecific LBP. Two months prior, she was involved in a motor vehicle accident (MVA) and was cared for in the emergency department of a local hospital. Imaging was negative and she was given a muscle relaxant, Cyclobenzaprine, for muscle spasms. ${ }^{12}$ During her physical therapy visit, English comprehension was limited and required the use of a telephone interpreter to address the language discordance. Reported pain had only decreased slightly since her MVA, and she was fearful of pain provoking movements. Sitting, standing, and walking for more than 15 minutes caused pain; stair climbing and lifting objects $>5$ pounds and caring for her two children was difficult. She had resigned from her sitting-focused job. Her goals were to be able to sit to return to work and to drive her children to school, and to walk and navigate stairs with decreased pain to make household activities and community outings easier. Other pertinent health information included prediabetes and class 1 obesity with a BMI of 31.0. A summary of the systems review can be found in Table 1.

Table 1. Systems Review

\begin{tabular}{|c|c|c|}
\hline System & Finding & Decision and Rationale \\
\hline Cognitive/Communication & $\begin{array}{l}\text { - Primarily Spanish-speaking. Use of } \\
\text { telephone interpreter required for } \\
\text { communication. } \\
\text { - Alert and oriented to person, place, time } \\
\text { and situation. }\end{array}$ & $\begin{array}{l}\text { System at risk. Telephone } \\
\text { interpretation expected to slow } \\
\text { and complicate communication. }\end{array}$ \\
\hline Musculoskeletal & $\begin{array}{ll}\text { - } & \text { High levels of low back pain } \\
\text { - } & \text { Pain with sitting, standing, walking, and } \\
\text { lifting } \\
\text { - } \quad \text { Reports difficulty navigating household } \\
\text { stairs and completing daily tasks }\end{array}$ & $\begin{array}{l}\text { Impaired. Low back motion } \\
\text { limited and painful, Spanish- } \\
\text { translated patient reported } \\
\text { outcome measure, and } \\
\text { complete lumbar exam } \\
\text { warranted. }\end{array}$ \\
\hline Integumentary & - No abnormalities noted & $\begin{array}{l}\text { No indication that system was at } \\
\text { risk }\end{array}$ \\
\hline Neuromuscular & $\begin{array}{l}\text { No complaints of radiating symptoms, } \\
\text { sensation changes, or changes in bowl } \\
\text { or bladder function recently. }\end{array}$ & $\begin{array}{l}\text { No indication that system was at } \\
\text { risk. }\end{array}$ \\
\hline
\end{tabular}




\begin{tabular}{|c|c|l|}
\hline Cardiovascular/Pulmonary & $\begin{array}{l}\text { No low back or regional swelling } \\
\text { observed }\end{array}$ & $\begin{array}{l}\text { Comorbid condition of obesity } \\
\text { puts her cardiovascular system } \\
\text { at an increased risk; system was } \\
\text { not cleared and should have } \\
\text { been assessed. }\end{array}$ \\
\hline Social/Emotional & $\begin{array}{l}\text { Distressed that pain has not diminished } \\
\text { since ED visit }\end{array}$ & $\begin{array}{l}\text { System at risk, follow up } \\
\text { discussion with the patient as } \\
\text { well as monitoring throughout } \\
\text { treatment course warranted. }\end{array}$ \\
\hline $\begin{array}{l}\text { Reports having to quit her job and that } \\
\text { she is unable to complete normal daily } \\
\text { activities }\end{array}$ & \\
\hline
\end{tabular}

\section{Physical Examination}

Gait was slow and antalgic with shortened stride length bilaterally. Midline lumbar and sacral pain was localized without radiating symptoms. Sit to stand transfers were difficult. Isolated hip ROM was within normal limits and pain free. Lumbopelvic ROM was limited and painful in both flexion and extension; however, the patient exhibited a slight flexion preference. All neurodynamic testing was negative and lumbar passive intervertebral accessory motion (PIAM) increased localized pain symptoms without radiation. Sacroiliac (SI) joint tests and prone instability test (PIT test) provoked local pain.

\section{Outcome Measures}

The Spanish Translation of the Oswestry Disability Index (ODI) and active lumbar flexion and extension ROM were prioritized as outcome measures throughout the course of treatment. The ODI includes one pain item and 9 activities of daily living items and was used to asses self-perceived disability. ${ }^{13}$ The Spanish translated and transculturally adapted version has very good internal consistency and good construct validity.14,15 Thoraco-lumbo-pelvic-hip (TLPH) ROM using a single bubble inclinometer is reliable and valid, demonstrating good inter- and intra-rater reliability as well as good construct validity. ${ }^{16}$ Psychometric data on lumbar ROM and the ODI can be found in Table 2.

Table 2. Outcome Measures

\begin{tabular}{|c|c|c|c|c|c|}
\hline & Reliability & Validity & Responsiveness & Error & Patient Data \\
\hline $\begin{array}{l}\text { Spanish } \\
\text { Translated } \\
\text { Oswestry } \\
\text { Disability Index }\end{array}$ & $\begin{array}{c}\text { Internal consistency: } \\
0.92^{14}\end{array}$ & $\begin{array}{c}\text { Construct validity: } \\
0.88^{14}\end{array}$ & $\begin{array}{c}\text { MDC }^{*}: 11.117 \\
\text { MCID*: } 12.88^{18}\end{array}$ & $\begin{array}{l}\text { SEM: } \\
4.02^{17}\end{array}$ & $\begin{array}{l}\text { Initial: } 38 \\
\text { Final: } 10\end{array}$ \\
\hline $\begin{array}{l}\text { Thoracolumbo- } \\
\text { pelvic hip ROM }\end{array}$ & $\begin{array}{c}\text { Flexion: } \\
\text { Intrarater: } 0.96^{16} \\
\text { Interrater: } 0.97^{16} \\
\text { Extension: } \\
\text { Intrarater: } 0.88^{16} \\
\text { Interrater: } 0.91^{16}\end{array}$ & $\begin{array}{c}\text { Flexion: } 0.98^{16} \\
\text { Extension: } 0.91^{16}\end{array}$ & $\begin{array}{l}\text { Flexion MDC: } 7 \\
\quad \text { degrees } \\
\text { Extension MDC: } 6 \\
\quad \text { degrees }^{16}\end{array}$ & - & $\begin{array}{c}\text { Initial } \\
\text { Flexion: } 45 \\
\text { Extension: } 10 \\
\\
\text { Final } \\
\text { Flexion: } 98 \\
\text { Extension: } 22\end{array}$ \\
\hline \multicolumn{6}{|c|}{$\begin{array}{l}{ }^{*} \text { Data for MDC and MCID was not available for the Spanish version of the ODI and therefore psychometrics from English } \\
\text { version is listed } \\
\text { Abbreviations: MDC, Minimal Detectable Change; MCID, Minimal Clinical Important Difference; SD, Standard Deviation; SEM } \\
\text { Standard Error of Measurement }\end{array}$} \\
\hline
\end{tabular}

Clinical Impression The language discordance was expected to impact PNE treatment and overall rehabilitation of impairments, activity limitations, and participation restrictions. High levels of pain, movement impairments, limited lumbar range of motion, and weakness of abdominal and hip musculature, limited sitting, standing, ambulating, and lifting were all observed. These led to participation restrictions in working, completing household chores, and caring for her children. Based on the treatment based classification system for low back pain, the patient's younger age, positive prone instability (PIT) test, and aberrant motions during functional movements placed her in the stabilization group. ${ }^{19}$ 


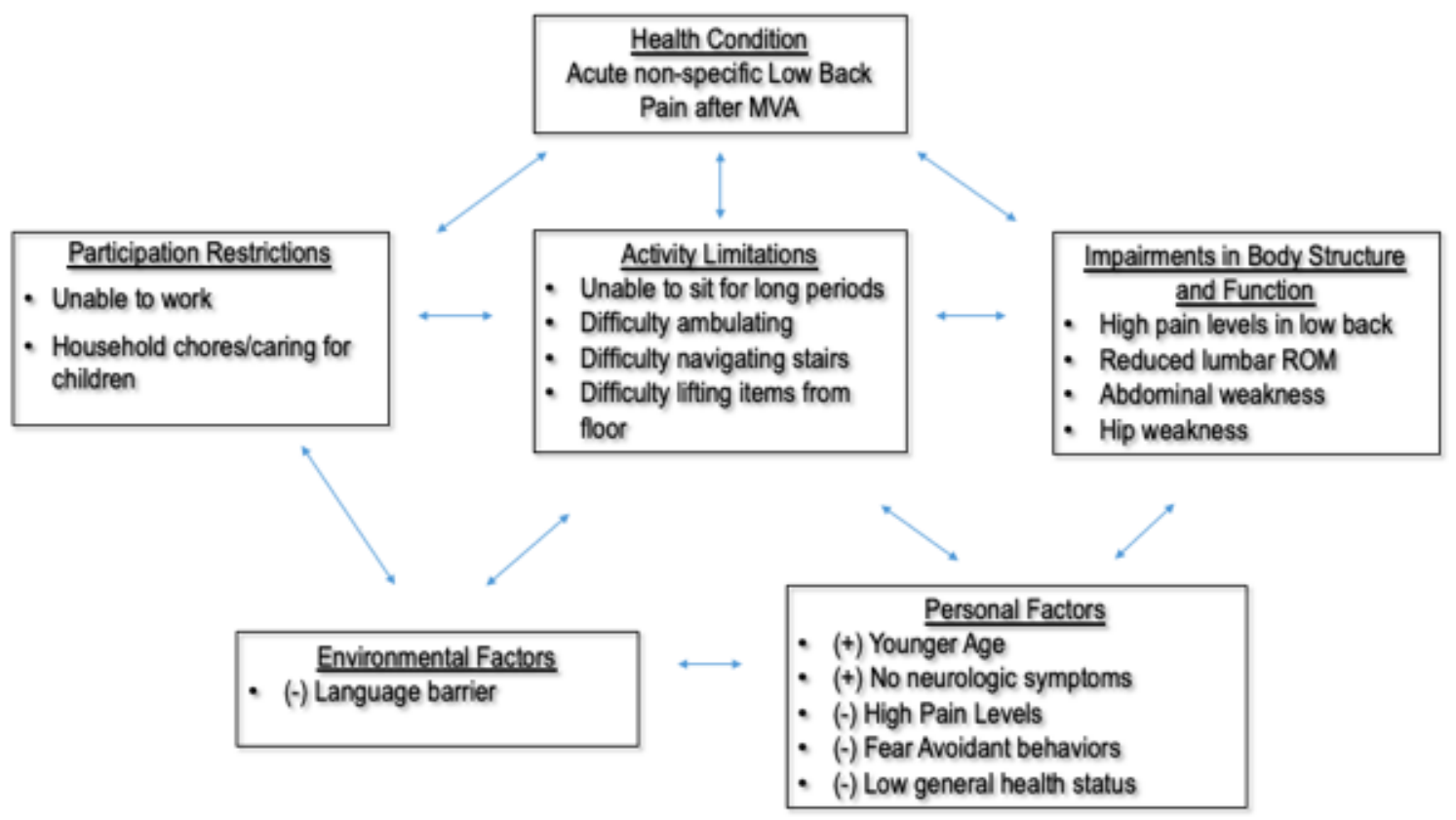

Abbreviations: MVA, Motor Vehicle Accident; ROM, Range of Motion

Figure 1. International Classification of Function (ICF) Model

\section{Prognosis}

Medical and functional prognoses were fair for return to desired activities; however, the language discordance was expected to negatively impact PNE treatment, and therefore, negatively impact the patient's prognosis. ${ }^{18-21}$ The medical prognosis, which can be measured by long term pain, and the functional prognosis, which can be measured by long term disability, were determined by the self-limiting nature of acute LBP as well as several personal and environmental factors. Further negative prognostic factors consisted of potential fear avoidant behaviors, high levels of pain, and low general health status. ${ }^{20,21}$ Positive prognostic factors included no neurological symptoms, role as a mother, and young age. 20-22

Several individual factors influenced her medical and functional prognosis, including the language discordance. Literature is limited on the impact of language discordance on acute LBP outcomes, but it negatively impacts general healthcare outcomes. Spanish speaking individuals who are not comfortable speaking English report worse health outcomes. ${ }^{2,3}$ Those using an interpreter during an emergency department visit were less likely to find their provider friendly, respectful, concerned, and inclined to make the patient feel comfortable. ${ }^{23} \mathrm{~A}$ good physical therapist-patient relationship is linked to increased treatment satisfaction in patients with musculoskeletal conditions. ${ }^{24}$ Due to the worse general health outcomes as well as the adverse impact on the patient-provider relationship, the patient's language discordance was hypothesized to negatively impact both her medical and functional prognosis.

Likelihood of long term LBP and disability is decreased if the patient is younger, has children, and lacks neurologic symptoms. ${ }^{21}$ However, negative prognostic factors included fear avoidance and greater than $6 / 10$ back pain at baseline which are associated with worse pain and disability outcomes at 1 year. ${ }^{20}$ Fear avoidance behaviors, such as quitting her job to avoid pain, were observed. Low general health status including prediabetes and class one obesity, are negative prognostic factors for recovery of acute LBP. ${ }^{26}$ These negative prognostic factors, in conjunction with the language discordance, were expected to negatively impact patient recovery.

While the prognosis for acute LBP can be complicated by individual factors, it is generally good due to the relatively rapid resolution of both pain and disability. A majority of individuals do not seek care for LBP as it is typically a mild and non-disabling health 
condition. ${ }^{27}$ A meta-analysis of 43 articles with a total of 11,166 participants reported that most patients with acute LBP recovered within 12 weeks and the most marked improvements in pain and disability occurred during the first 6 weeks. ${ }^{28}$ In acute LBP, pain and disability appear to be closely correlated and follow the same timeline. ${ }^{28,20}$ However, when LBP transitions to chronic or persistent pain, pain outcomes tend to be worse than disability outcomes and the correlation weakens. ${ }^{28}$ Overall, the self-limiting nature of acute low back pain in conjunction with individual patient factors lead for an expected fair medical and functional prognosis for return to desired activities.

\section{Plan of Care}

The plan included 12 visits over 12 weeks including PNE, manual therapy, and therapeutic exercise to help the patient return to work and have less difficulty completing household chores and caring for her children. The planned intervention included using a telephone interpreter from an off-site interpretation service that does not specialize in medical interpretation to deliver PNE intervention. Increased PNE intervention time was expected due to delay of communication when using interpretation services. Pain neuroscience education shows promise for improving pain and disability outcomes in acute LBP; furthermore, individuals with higher pain levels and fear avoidance behaviors are more likely to respond well to PNE.6,29-31 The overall goals included enhanced patient understanding of PNE concepts, progressive return to activities, and increased abdominal and hip strength.

\section{Intervention}

A variety of interventions were utilized with the patient to decrease pain that was limiting her work, household chores, and care of her children. Pain neuroscience education focused on the biological and physiological processes that occur with pain and avoiding focus on tissues and anatomical structures. ${ }^{32}$ Short verbal explanations were translated by a telephone interpreter. There was a limit to PNE depth due to translation and variable translator proficiency in medical terminology; the interpreters would often ask clarifying questions because they did not understand what they were meant to interpret or did not know how to say PNE terminology in Spanish. A typical PNE intervention when utilizing the off-site telephone interpreter would take 15 to 20 minutes of a 30 minute session; in the same setting, the therapist could perform a PNE intervention in 5 to 10 minutes when no language discordance was present. PNE intervention content is described in Table 4. Strengthening of the hip musculature, stabilization exercises, and body mechanics training were utilized to decrease pain and enhance performance with lifting, which was limiting the patient in her household chores. Directional preference exercises that initially focused on flexion and transitioned to extension bias were included to increase the patient's tolerance of extension-based activities, such as standing and ambulating. Manual therapy (MT) was a planned intervention to reduce pain levels, however, the patient did not tolerate MT and it was discontinued after the first session. Graded exposure to stairs was included in treatment due to the patient's high pain levels while navigating stairs and avoidance of the activity. While the original plan included 12 weeks of treatment, therapy was discontinued after week 5 due to reduced clinic operations during the COVID-19 pandemic. A timeline of specific interventions can be found in Table 3.

Table 3. Interventions by Week

\begin{tabular}{|l|c|c|c|c|c|}
\hline \multicolumn{1}{|c|}{ Intervention Category } & Week 1 & Week 2 & Week 3 & Week 4 & Week 5 \\
\hline PNE & $\mathrm{X}$ & $\mathrm{X}$ & $\mathrm{X}$ & $\mathrm{X}$ & \\
\hline PNE Applied to Function & & & $\mathrm{X}$ & $\mathrm{X}$ & $\mathrm{X}$ \\
\hline Strengthening & $\mathrm{X}$ & $\mathrm{X}$ & $\mathrm{X}$ & $\mathrm{X}$ & $\mathrm{X}$ \\
\hline $\begin{array}{l}\text { Directional Preference } \\
\text { Exercises }\end{array}$ & $\mathrm{X}$ & $\mathrm{X}$ & $\mathrm{X}$ & $\mathrm{X}$ & $\mathrm{X}$ \\
\hline Manual Therapy & $\mathrm{X}$ & & & \\
\hline Body Mechanics Training & & & & $\mathrm{X}$ \\
\hline $\begin{array}{l}\text { Abbreviations: PNE, Pain Neuroscience Education } \\
{ }^{*} \text { Refers to using graded exposure, see table 4 for more detail }\end{array}$
\end{tabular}

Table 4. Pain Neuroscience Education

\begin{tabular}{|l|l|}
\hline \multicolumn{1}{|c|}{ PNE Topic } & \multicolumn{1}{c|}{ Content } \\
\hline Pain and Nociception & $\begin{array}{l}\text { The therapist described the difference between nociception and pain and that pain can } \\
\text { be present without nociception. Just because pain is present does not mean that there is } \\
\text { serious tissue damage. }\end{array}$ \\
\hline Sensitization and Pain Threshold & $\begin{array}{l}\text { When pain has been present for a while, nerves can become extra sensitive to a } \\
\text { stimulus. Movement or touch that would normally not cause pain can be excruciating. } \\
\text { Sensitization occurs because the nerves become easier to excite and send messages of }\end{array}$ \\
\hline
\end{tabular}




\begin{tabular}{|l|l|}
\hline & $\begin{array}{l}\text { pain more readily. If you continue to limit movement and touch, this threshold gets lower } \\
\text { and lower. }\end{array}$ \\
\hline Graded Exposure and Pain & $\begin{array}{l}\text { When painful movements are avoided, the range of tolerable motion becomes smaller } \\
\text { and smaller. Exposure to movements and activities that are painful helps to increase } \\
\text { tolerance for these activities, and eventually the goal is to desensitize and feel less pain } \\
\text { while performing activities. }\end{array}$ \\
\hline Fear and Anxiety & $\begin{array}{l}\text { Feeling fearful and anxious about pain can make the pain worse and can lead to } \\
\text { maladaptive and fear avoidant behaviors. Behaviors that avoid pain can lead to other } \\
\text { body impairments and increased sensitivity of the nervous system. }\end{array}$ \\
\hline Exercise and Pain & $\begin{array}{l}\text { Pain can inhibit muscular activation or alter normal muscle firing patterns. Exercise is } \\
\text { important to help modulate pain, maintain and/or improve function, and decrease muscle } \\
\text { inhibition. }\end{array}$ \\
\hline Function & $\begin{array}{l}\text { It is important to track functional progress as well as pain progress. When pain } \\
\text { processing is altered or sensitized, changes can take a while to occur in pain levels. } \\
\text { Function is often faster to improve. It is important to notice when more functional } \\
\text { activities are able to be completed without pain levels increasing and see this as } \\
\text { progress. }\end{array}$ \\
\hline Graded Exposure & $\begin{array}{l}\text { Exposing a patient to an activity that they are fearful of in a safe environment can help } \\
\text { reduce fear and pain associated with the activity. This is a functional way to apply PNE } \\
\text { to painful activities. It is important to understand that some pain with activity is ok and to } \\
\text { change the pain threshold, it is important to do some activities that may be painful. }\end{array}$ \\
\hline Derived from "Explain Pain Supercharged."33 \\
\hline
\end{tabular}

\section{RESULTS}

Despite the challenges associated with providing PNE intervention via a telephone interpreter, the patient experienced significant improvement in outcomes. Reported pain levels on the NPRS decreased from a 7/10 to a 3/10 with activity and from a 4/10 to a $0 / 10$ at rest at week 5 , surpassing the 2 point minimal clinical important difference (MCID). ${ }^{34}$ Within 3 weeks, the patient was able to tolerate extension-based exercises with 3/10 or lower pain on the NPRS, whereas on initial examination, extension caused the patient $7 / 10$ pain. Functional mobility improved with ability to ambulate without gait deviations and move from sitting to standing without use of her upper extremities by week 3 , and ascend and descend stairs by week 4 , all while experiencing decreased pain levels. The ODI improved from $38 \%$ week 1 to $10 \%$ week 5 , which is considered minimal disability (Figure 2). This change was greater than the minimal clinical important difference (MCID) of 12.88\%. ${ }^{18} \mathrm{Her}$ TLPH ROM improved from 45 to 98 degrees of flexion, and from 10 to 22 degrees of extension from initial evaluation to the final visit and observation showed increased lumbar spine motion (Figure 3). The minimal detectable change (MDC) for TLPH ROM is 7 degrees for flexion and 6 degrees for extension, both of which were exceeded. ${ }^{16}$ The patient reported being able to navigate the stairs in her home, lift objects up to 5 pounds, and sit and walk for greater than 30 minutes at the final visit.

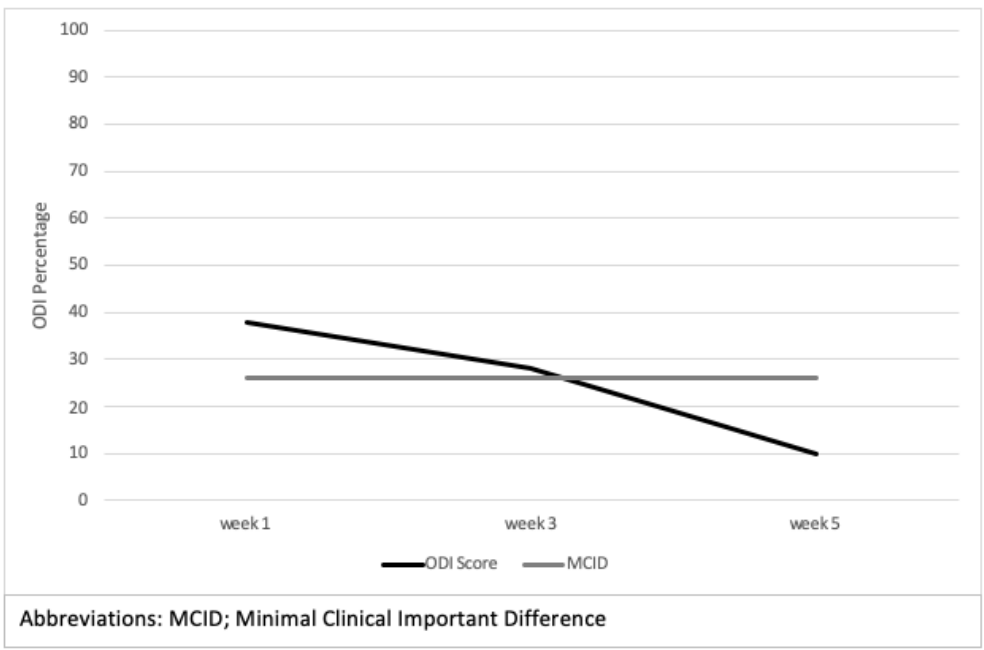

Figure 2. Oswestry Disability Index Score 


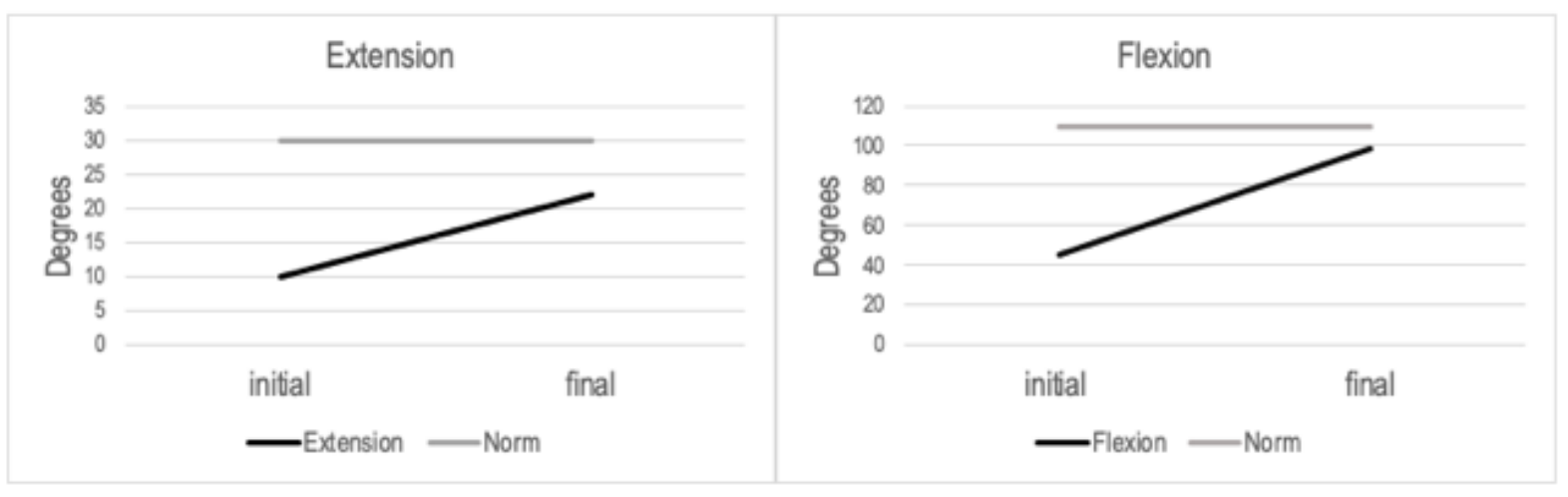

Figure 3. Thoracolumbar pelvic hip range of Motion

\section{CONCLUSIONS}

This case report discusses the physical therapist management of a Spanish speaking patient with acute LBP and the impacts that a language discordance can have on the PNE treatment. Pain neuroscience education was utilized as a primary intervention due to its efficacy in reducing musculoskeletal pain and the patient's high pain levels and fear avoidance behaviors. $30-32$ Strengthening, stabilization and directional preference exercises, graded exposure and body mechanics training were also key interventions. Over 5 weeks of treatment, ODI score reduction was clinically meaningful and the patient was able to meet her goals of being able to navigate stairs, lift greater than 5 pounds, and sit and walk for greater than 30 minutes. While delivery of PNE was more time consuming with use of a translation service, the patient saw meaningful improvements over 5 weeks; and PNE appears to still be an effective physical therapy intervention when delivered via translation service.

Current literature is emerging to support the use of PNE in acute low back pain; however, there is limited literature on the impact of language discordance on PNE treatment. 6,29 General healthcare research suggests health outcomes are worse for individuals who do not speak the dominant language and that the patient-provider relationship can be adversely impacted by a language discordance. ${ }^{2,3,23}$ Pain neuroscience education is a treatment that relies on clear communication and a therapeutic alliance between the patient and provider to be successful. ${ }^{10}$ Method of interpretation also appears to be important; evidence has shown that offsite telephone interpreting services lead to lower patient satisfaction. ${ }^{4}$ The therapist was required to use very brief and surface level explanations in order for the telephone interpreter to be able to translate. Time of intervention was also increased due to delay of communication when using an interpreter. However, even with the challenging circumstances of having a language discordance and the use of a telephone interpreter to deliver PNE, function improved over a relatively short period of time.

Although the outcomes were positive for the patient during her course of physical therapy, it was difficult to judge the success of PNE as an intervention. The most common natural progression for acute LBP is resolution within 12 weeks, and 12 weeks had passed since initial injury. ${ }^{28}$ Therefore, her positive outcomes could be attributed to the self-limiting nature of her health condition. Furthermore, other interventions used in the patient's treatment have research supporting their use in acute LBP and could have contributed to her improvements. ${ }^{35}$

Several examination items would have provided a more complete picture of the patient. The cardiovascular system should have been assessed due to the patient's medical history of class 1 obesity; individuals who are obese have a higher risk of cardiovascular disease. ${ }^{36} \mathrm{~A}$ formal measure of fear avoidance would have been helpful because fear does not always present with physical signs. The Spanish version of the Fear Avoidance Beliefs Questionnaire (FABQ) is validated and therefore could have easily been used with this patient. ${ }^{37}$ Finally, to assess patient understanding of PNE, the therapist could have used a teach back method or the Revised Neurophysiology of Pain Questionnaire (RNPQ). A teach back method would have consisted of the patient summarizing what the therapist had taught in their own words and would have highlighted any gaps or confusion in the education. The RNPQ could have been used to gather quantitative data about the patient's baseline pain knowledge as well as the effectiveness of PNE.

The physical therapist could have used other resources to aid in PNE. Practice guidelines for PNE suggest using written materials alongside in-person educational sessions. There are PNE materials available in Spanish. ${ }^{38,39}$ These are easily accessible and could have been used to supplement the PNE intervention. Furthermore, these written materials could have been given as part of 
the home exercise program which could have reduced the amount of time within sessions dedicated to PNE and made the intervention less time consuming.

The link between clarity of communication and patient comprehension, outcomes, and satisfaction in physical therapy management is unclear. Research on PNE education delivered with a telephone interpreter would be beneficial as would assessment of the best method of interpretation (in person, video, telephone, etc.). Furthermore, research should be conducted about patient satisfaction and outcomes with physical therapy treatment when a language discordance is present, especially because the therapist-patient alliance is essential for effective treatment. While further research is needed, this case report provided a discussion of specific intervention techniques, including use of PNE, in the physical therapy management of a patient with a language discordance; it is important for physical therapy providers to consider how a language discordance may impact the effectiveness of their treatment and may influence patient comprehension, outcomes, and satisfaction.

\section{REFERENCES}

1. Sears J, Khan K, Ardern Cl, Tamim H. Potential for patient-physician language discordance in Ontario. BMC Health Serv Res. 2013;13:535. doi:10.1186/1472-6963-13-535. [PMID 24373325]

2. Cheng EM, Chen $A$, Cunningham W. Primary language and receipt of recommended health care among Hispanics in the United States. J Gen Intern Med. 2007;22(S2):283-288. doi:10.1007/s11606-007-0346-6. [PMID 17957412]

3. C. Annette DuBard, Ziya Gizlice. Language Spoken and Differences in Health Status, Access to Care, and Receipt of Preventive Services Among US Hispanics | AJPH | Vol. 98 Issue 11. Popul Div US Census Bur. Published online November 2008. Accessed June 11, 2020. https://ajph.aphapublications.org/doi/full/10.2105/AJPH.2007.119008. [PMID 18799780]

4. Joseph C, Garruba M, Melder A. Patient satisfaction of telephone or video interpreter services compared with in-person services: a systematic review*. Aust Health Rev. 2018;42(2):168-177. doi:10.1071/AH16195. [PMID 30021688]

5. Mirza M, Harrison EA, Roman M, Miller KA, Jacobs EA. Walking the talk: understanding how language barriers affect the delivery of rehabilitation services. Disabil Rehabil. 2020;0(0):1-14. doi:10.1080/09638288.2020.1767219. [PMID 32478575]

6. Louw A, Farrell K, Choffin B, et al. Immediate effect of pain neuroscience education for recent onset low back pain: an exploratory single arm trial. J Man Manip Ther. Published online June 4, 2019. [PMID 31161919]

7. Luo X, Pietrobon R, X Sun S, Liu GG, Hey L. Estimates and patterns of direct health care expenditures among individuals with back pain in the United States. Spine. 2004;29(1):79-86. doi:10.1097/01.BRS.0000105527.13866.0F. [PMID 14699281]

8. Gatchel RJ, Bernstein D, Stowell AW, Pransky G. Psychosocial differences between high-risk acute vs. chronic low back pain patients. Pain Pract. 2008;8(2):91-97. doi:10.1111/j.1533-2500.2008.00176.x. [PMID 18366464]

9. A Louw, I Diener, DS Butler, EJ Puentedura. The effect of neuroscience education on pain, disability, anxiety, and stress in chronic musculoskeletal pain. Arch Phys Med Rehabil. 2011;92(12):2041-2056. [PMID 22133255]

10. Wijma AJ, Speksnijder CM, Crom-Ottens AF, et al. What is important in transdisciplinary pain neuroscience education? A qualitative study. Disabil Rehabil. 2018;40(18):2181-2191. doi:10.1080/09638288.2017.1327990. [PMID 28524700]

11. Ortman JM, Hyon B. Shin. Language projections: 2010 to 2020. Presented at the: Annual Meetings of the American Sociological Association; August 20, 2011; Las Vegas, NV.

12. IBM Micromedex DRUGEX (electronic version). IBM Watson Health. Accessed June 13, 2020. https://wwwmicromedexsolutions-com.proxy.hsl.ucdenver.edul

13. Smeets R, Köke A, Lin C-W, Ferreira M, Demoulin C. Measures of function in low back pain/disorders: Low Back Pain Rating Scale (LBPRS), Oswestry Disability Index (ODI), Progressive Isoinertial Lifting Evaluation (PILE), Quebec Back Pain Disability Scale (QBPDS), and Roland-Morris Disability Questionnaire (RDQ). Arthritis Care Res. 2011;63(S11):S158-S173. doi:10.1002/acr.20542. [PMID 22588742]

14. Selva-Sevilla C, Ferrara P, Gerónimo-Pardo M. Psychometric properties study of the Oswestry Disability Index in a Spanish population with previous lumbar disc surgery: homogeneity and validity. SPINE. 2019;44(7):E430-E437. doi:10.1097/BRS.0000000000002867. [PMID 30234803]

15. Fairbank JCT, Pynsent PB. The Oswestry Disability Index. Spine. 2000;25(22):2940-2953. [PMID 11074683]

16. Kolber MJ, Pizzini M, Robinson A, Yanez D, Hanney WJ. The Reliability and Concurrent Validity of Measurements used to Quantify Lumbar Spine Mobility: An Analysis of an iPhone Application and Gravity Based Inclinometry. Int J Sports Phys Ther. 2013;8(2):129-137. [PMID 23593551]

17. Grotle M, Garratt AM, Krogstad Jenssen H, Stuge B. Reliability and construct validity of self-report questionnaires for patients with pelvic girdle pain. Phys Ther. 2012;92(1):111-123. doi:10.2522/ptj.20110076. [PMID 16540864]

18. Johnsen LG, Hellum C, Nygaard OP, et al. Comparison of the SF6D, the EQ5D, and the oswestry disability index in patients with chronic low back pain and degenerative disc disease. BMC Musculoskelet Disord. 2013;14:148. doi:10.1186/1471-2474-14-148. [PMID 20447871] 
19. Brennan GP, Fritz JM, Hunter SJ, Thackeray A, Delitto A, Erhard RE. Identifying subgroups of patients with acute/subacute "nonspecific" low back pain: results of a randomized clinical trial. Spine. 2006;31(6):623-631. doi:10.1097/01.brs.0000202807.72292.a8. [PMID 16677837]

20. Jensen OK, Nielsen CV, Stengaard-Pedersen K. One-year prognosis in sick-listed low back pain patients with and without radiculopathy. Prognostic factors influencing pain and disability. Spine J. 2010;10(8):659-675. doi:10.1016/j.spinee.2010.03.026. [PMID 20227639]

21. Grotle M, Brox JI, Glomsrød B, Lønn JH, Vøllestad NK. Prognostic factors in first-time care seekers due to acute low back pain. Eur J Pain. 2007;11(3):290-298. doi:10.1016/j.ejpain.2006.03.004. [PMID 16371911]

22. J.A. Hayden, K.M. Dunn, D.A. van der Windt, W.S. Shaw. What is the prognosis of back pain? Best Pract Res Clin Rheumatol. 2010;24(2):167-179. doi:10.1016/j.berh.2009.12.005. [PMID 22586331]

23. Baker DW, Hayes R, Fortier JP. Interpreter use and satisfaction with interpersonal aspects of care for Spanish-speaking patients. Med Care. 1998;36(10):1461-1470. [PMID 8455963]

24. Hall AM, Ferreira PH, Maher CG, Latimer J, Ferreira ML. The influence of the therapist-patient relationship on treatment outcome in physical rehabilitation: a systematic review. Phys Ther. 2010;90(8):1099-1110. doi:10.2522/ptj.20090245. [PMID 20371789]

25. Waddell G, Newton M, Henderson I, Somerville D, Main CJ. A Fear-Avoidance Beliefs Questionnaire (FABQ) and the role of fear-avoidance beliefs in chronic low back pain and disability. Pain. 1993;52(2):157-168. doi:10.1016/03043959(93)90127-B. [PMID 24252071]

26. Chou R, Shekelle P. Will this patient develop persistent disabling low back pain? JAMA. 2010;303(13):1295-1302. doi:10.1001/jama.2010.344. [PMID 28820626]

27. Cassidy JD, Côté P, Carroll LJ, Kristman V. Incidence and course of low back pain episodes in the general population. Spine. 2005;30(24):2817-2823. doi:10.1097/01.brs.0000190448.69091.53. [PMID 9794340]

28. Costa L da CM, Maher CG, Hancock MJ, McAuley JH, Herbert RD, Costa LOP. The prognosis of acute and persistent lowback pain: a meta-analysis. CMAJ. 2012;184(11):E613-E624. doi:10.1503/cmaj.111271. [PMID 20576715]

29. Zimney K, Louw A, Puentedura EJ. Use of therapeutic neuroscience education to address psychosocial factors associated with acute low back pain: a case report. Physiother Theory Pract. 2014;30(3):202-209. doi:10.3109/09593985.2013.856508. [PMID 28694679]

30. Louw A, Puentedura EJ, Zimney K, Cox T, Rico D. The clinical implementation of pain neuroscience education: a survey study. Physiother Theory Pract. 2017;33(11):869-879. doi:10.1080/09593985.2017.1359870. [PMID 27351541]

31. Louw A, Nijs J, Puentedura EJ. A clinical perspective on a pain neuroscience education approach to manual therapy. J Man Manip Ther. 2017;25(3):160-168. doi:10.1080/10669817.2017.1323699. [PMID 15928561]

32. Louw A, Zimney K, Puentedura EJ, Diener I. The efficacy of pain neuroscience education on musculoskeletal pain: a systematic review of the literature. Physiother Theory Pract. 2016;32(5):332-355. doi:10.1080/09593985.2016.1194646. [PMID 23622053]

33. G. Lorimer Moseley, David Sheridan Butler. Explain Pain Supercharged. NOI Group Publications; 2017. [PMID 22247407]

34. Childs JD, Piva SR, Fritz JM. Responsiveness of the Numeric Pain Rating Scale in patients with low back pain. Spine. 2005;30(11):1331-1334. doi:10.1097/01.brs.0000164099.92112.29. [PMID 1995775]

35. Surkitt LD, Ford JJ, Hahne AJ, Pizzari T, McMeeken JM. Efficacy of Directional Preference Management for Low Back Pain: A Systematic Review. Phys Ther. 2012;92(5):652-665. doi:10.2522/ptj.20100251. [PMID 16395186]

36. Kannel WB, Adrienne Cupples L, Ramaswami R, Stokes J, Kreger BE, Higgins M. Regional obesity and risk of cardiovascular disease; the Framingham study. J Clin Epidemiol. 1991;44(2):183-190. doi:10.1016/0895-4356(91)90265-B. [PMID 21632273]

37. Kovacs FM, Muriel A, Medina JM, et al. Psychometric characteristics of the Spanish version of the FAB Questionnaire. Spine. 2006;31(1):104-110. doi:10.1097/01.brs.0000193912.36742.4f

38. Nijs J, Paul van Wilgen C, Van Oosterwijck J, van Ittersum M, Meeus M. How to explain central sensitization to patients with 'unexplained' chronic musculoskeletal pain: practice guidelines. Man Ther. 2011;16(5):413-418. doi:10.1016/j.math.2011.04.005. [PMID 22016375]

39. Brandworks.be. Pain in Motion. Accessed December 8, 2020. http://www.paininmotion.be/education/tools-for-clinicalpractice 